\title{
Aplicação de técnicas de sensoriamento remoto na investigação do controle do posicionamento do Complexo Carbonatítico Seis Lagos e no estudo do depósito (Nb) laterítico associado (Amazonas, Brasil)
}

\author{
Marco B. ROSSONI ${ }^{1}$, Artur C. BASTOS NETO ${ }^{2}$, Dejanira L. SALDANHA ${ }^{2}$, Valmir S. SOUZA ${ }^{3}$, Arthur \\ L. GIOVANNINI ${ }^{1} \&$ Claudio G. PORTO ${ }^{4,5}$
}

(1) Programa de Pós-graduação em Geociências, Instituto de Geociências, Universidade Federal do Rio Grande do Sul. Av. Bento Gonçalves, 9500, Porto Alegre, CEP 91.540-000, RS, Brasil. E-mail: marco_rossoni@hotmail.com, arthur_giovannini@hotmail.com.

(2) Instituto de Geociências, Universidade Federal do Rio Grande do Sul. Av. Bento Gonçalves 9500, CEP 91.540000, Porto Alegre, RS, Brasil. E-mail: artur.bastos@ufrgs.br, dejanira.saldanha@ufrgs.br.

(3) Instituto de Geociências, Universidade de Brasília. Campus Darcy Ribeiro, Asa Norte, CEP 70910-900, Brasília, DF, Brasil. E-mail: vsouza@unb.br.

(4) Divisão de Geoquímica, Companhia de Pesquisa de Recursos Minerais. Av. Pasteur, 404, CEP 22.290-240, Rio de Janeiro, RJ, Brasil. E-mail: claudio.porto@cprm.gov.br.

(5) Instituto de Geociências, Universidade Federal do Rio de Janeiro. Cidade Universitária, Ilha do Fundão, Av. Athos da Silveira Ramos, s/n, CEP 21949-900, Rio de Janeiro, RJ, Brasil. E-mail: porto@geologia.ufrj.br.

Recebido em 09/2014. Aceito para publicação em 04/2016.

Versão online publicada em 31/05/2016 (www.pesquisasemgeociencias.ufrgs.br)

\begin{abstract}
Resumo - Este estudo teve como objetivos principais identificar as estruturas geológicas que controlaram o posicionamento do Complexo Carbonatítico Seis Lagos, localizado no noroeste do Estado do Amazonas, e contribuir para o conhecimento da geologia do depósito associado, através da delimitação da crosta laterítica e identificação de estruturas internas e de zonas de alteração hidrotermal onde maiores concentrações de Nb e ETR podem ocorrer. Foram utilizados os métodos geofísicos aeromagnetometria, aerogamaespectometria e mapas de anomalia Bouger, análise de modelo digital de elevação e técnicas de processamento de dados orbitais. A principal estrutura regional tem direção geral E-W, extensão de cerca de $400 \mathrm{~km}$. 0 posicionamento do CCSL ocorreu onde ela é intersectada por estruturas de direção NE-SW e NW-SE. Os limites da crosta laterítica são em grande parte retilíneos, sugerindo estruturas rúpteis, sejam estas as paredes do conduto magmático, aberto seguindo falhas e fraturas, ou falhas que afetaram o corpo após sua cristalização. As principais estruturas afetando o depósito têm direção E-W ou NNW-SSE, controlaram a formação de vales e cristas, a atuação de processos cársticos com formação de bacias; exerceram, portanto, papel relevante durante o processo de lateritização. Zonas ricas em argilas indicativas de alteração hidrotermal foram identificadas em quatro estruturas.
\end{abstract}

Palavras-chave: nióbio, elementos terras raras, laterita.

\begin{abstract}
Remote SENSing APPLied to inVESTigate the Emplacement of the Seis Lagos CaRBonatitic Complex and the lateritic Nb-Deposit associated (AMAZonas State, Brazil). The main goals of this study were to identify geological structures that controlled the emplacement of the Seis Lagos Carbonatite Complex and contribute to the knowledge of the associated deposit, through the delimitation of the lateritic crust, the identification of internal structures and hydrothermal zones, where higher concentrations of $\mathrm{Nb}$ and REE may occur. Geophysical techniques, analysis of digital terrain elevation and processing techniques of orbital data were employed. The main regional structure has E-W direction and length of about $400 \mathrm{~km}$. The positioning of the SLCC occurred where it is intersected by structures trending NE-SW and NW-SE. The boundaries of the lateritic crust are largely rectilinear, suggesting brittle structures, that may be the walls of the magma conduct, following open faults and fractures, or faults that affect the body after its crystallization. The main structures affecting the deposit have EW or NNW-SSE direction, controlled the formation of valleys and ridges, and karst processes with basin formation; therefore exerted role during laterization. Clayey zones likely related to hydrothermal processes were identified in four structures.
\end{abstract}

Keywords: Niobium, rare earth elements, laterite. 


\section{Introdução}

A aplicação da técnica de imageamento por radar, auxiliando a cartografia geológica e geomorfológica do Brasil, realizada pelo projeto RADAM-BRASIL na década de 1970, permitiu identificar diversas estruturas circulares na Amazônia, entre elas as três estruturas que constituem o Complexo Carbonatítico Seis Lagos, localizado no município de São Gabriel da Cachoeira, Estado do Amazonas. O nome "Seis Lagos" já foi utilizado em combinação com muitos outros termos, tais como morro, intrusão, carbonatito, complexo carbonatítico, complexo vulcânico e complexo alcalino. Neste trabalho, utiliza-se o termo Complexo Carbonatítico Seis Lagos (CCSL) para designar esse conjunto de três corpos circulares e o termo Morro dos Seis Lagos (MSL) para designar o corpo circular principal.

As sondagens efetuadas pela Companhia de Pesquisa de Recursos Minerais (CPRM) no MSL revelaram o maior depósito de $\mathrm{Nb}$ até hoje encontrado, com reserva estimada de $2.898 .10^{6} \mathrm{t}$, com teor médio de 2,81\% de $\mathrm{Nb}_{2} \mathrm{O}_{5}$ (Justo \& Souza, 1984, 1986). 0 depósito apresenta também concentrações anômalas de elementos terras raras (ETR) (Bonow \& Issler, 1980; Issler, 1980a, 1980b), que, na época, não apresentavam o extraordinário interesse tecnológico que possuem atualmente.

Recentemente, a China, que abastece $95 \%$ do mercado mundial de ETR, anunciou que vai dirigir toda a sua produção para o mercado interno, gerando uma corrida na pesquisa por novos depósitos de ETR e na investigação dos potenciais de outros depósitos para explotação destes elementos como subprodutos (Stone, 2009; Service, 2010). Desta forma, houve um maior interesse pelo detalhamento do depósito de Seis Lagos, cujos testemunhos estão sendo reestudados por uma equipe de pesquisadores da UFRGS e da CPRM, o que, por sua vez, motivou a realização deste estudo utilizando técnicas de sensoriamento remoto. Este trabalho tem como objetivos: (i) identificar a(s) estrutura(s) que controlam o posicionamento do corpo carbonatítico; (ii) identificar contextos estruturais semelhantes em áreas vizinhas, que possam representar zonas com potencial para outros corpos mineralizados de mesma natureza; (iii) precisar a delimitação do corpo carbonatítico e do depósito laterítico associado; e (iv) identificar estruturas e zonas de alteração hidrotermal no interior do corpo que possam representar zonas de enriquecimento do minério.

\section{2 Área, materiais e métodos}

\subsection{Geologia Regional}

O CCSL situa-se na porção oeste do Escudo das Guianas, norte do Cráton Amazonas (Figs. 1 e 2). Conforme Souza (2009), o avanço do conhecimento da geologia e geocronologia da Amazônia tem corroborado os modelos evolutivos do cráton, que se baseiam em conceitos de orogenias modernas e consideram que, durante o Arqueano e do Paleo ao Mesoproterozoico, ocorreram sucessivos arcos magmáticos com a formação de material juvenil derivado do manto, assim como processos subordinados de retrabalhamento crustal (Tassinari, 1981; Cordani \& Brito Neves, 1982; Tassinari \& Macambira, 1999, 2004; Santos et al., 2000, 2006). Entretanto, ainda existem divergências científicas quanto aos limites geográficos, nomes e idades dos eventos geotectônicos que consolidaram o Cráton Amazonas. Nesse sentido, o CCSL estaria inserido no contexto geotectônico do domínio Ventuari, proposto por Tassinari \& Macambira (1999), que seria aproximadamente equivalente ao domínio da província Rio Negro proposta por Santos et al. (2006).

A Província Rio Negro (Santos et al., 2000) comporta dois domínios tectono-estratigráficos principais (CPRM, 2006) (Fig. 3), Alto Rio Negro, a oeste (na região da "cabeça do cachorro"), e Imeri, a leste, o qual hospeda o CCSL (CPRM, 2006). 0 embasamento do domínio Imeri é representado pelo Complexo Cauaburi, o qual agrupa metagranitóides porfiríticos, ortognaises tonalíticos a monzoníticos, augen gnaisses, anfibolitos e migmatitos localizados, foliados na direção NE-SW (CPRM, 2002, 2006). Os poucos dados geocronológicos sobre essas rochas indicam idades em torno de 1,8 Ga (Santos et al., 2000; Santos, 2003; CPRM, 2006).

O domínio Imeri, particularmente, possui direção estrutural preferencial NE-SW assinalada pelo alinhamento de algumas serras, além de faixas internas com deformação heterogênea desenvolvida no seu embasamento, evidenciada por extensos lineamentos associados a expressivas zonas de cisalhamento; a direção NW-SE tem ocorrência mais restrita, mas é marcante em alguns casos (CPRM, 2006).

Segundo CPRM (2006), o Complexo Cauaburi é cortado por intrusões graníticas das suítes intrusivas Igarapé Reilau (tipo S), Marauiá e Marié-Mirim (ambas do tipo A) e Rio Uaupés. Souza (2009) divide os corpos graníticos da Província Rio Negro (Fig. 3) em granito tipo A, granitoide tipo $\mathrm{S}$ e gra- 


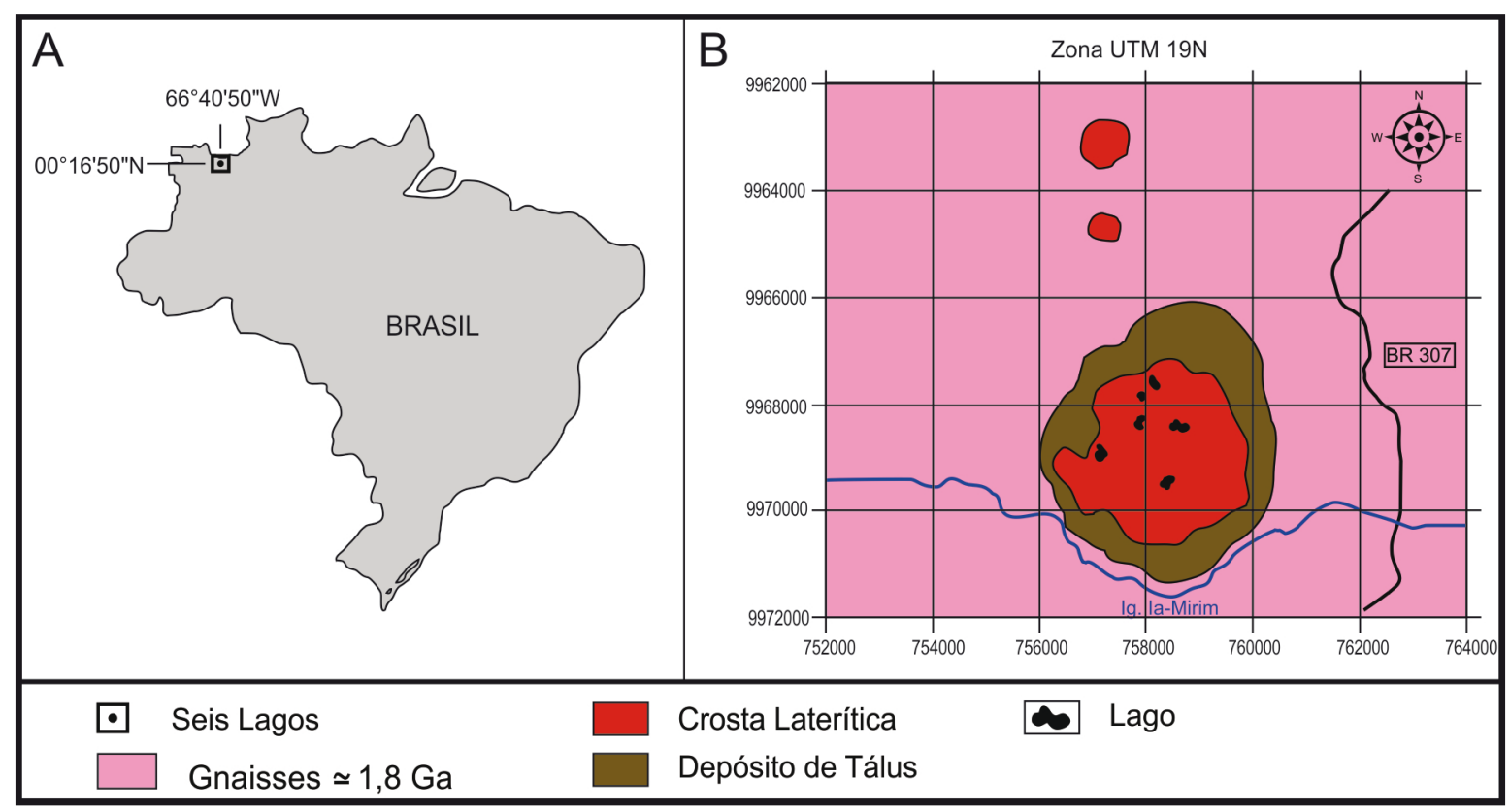

Figura 1. Localização da área de estudo. A) Localização do Complexo Carbonatítico Seis Lagos no mapa do Brasil; B) Mapa geológico simplificado do Complexo Carbonatítico Seis Lagos.

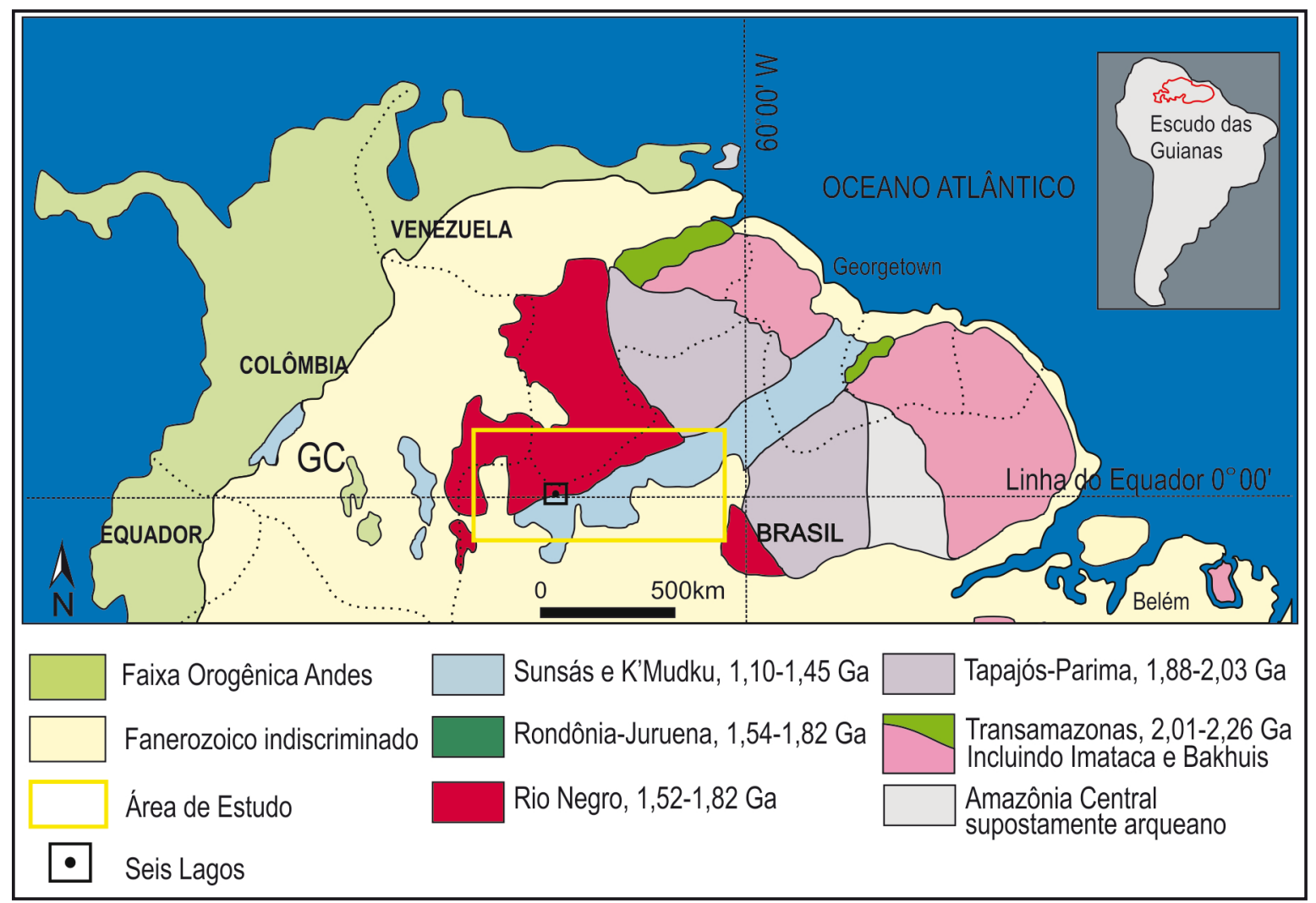

Figura 2. Localização da área estudada neste trabalho dentro do Escudo das Guianas, segundo a proposta de Santos et al. (2006).

nitoides proterozoicos. Estes últimos são os mais numerosos, sendo representados por monzogranitos, sienogranitos, granodioritos e granitoides deformados. Os granitos situados ao sul e a sudoeste do CCSL (Fig. 3) pertencem à Suíte Intrusiva Rio Uaupés. 0 termo granito Rio Uaupés (Dall'Agnol \& Macambira, 1992) designa titanita-biotita monzogranitos (tipo predominante) com idade $\mathrm{Rb}-\mathrm{Sr}$ de $1.459 \pm 32$ Ma e razão isotópica ${ }^{87} \mathrm{Sr} / \mathrm{Sr}^{86}$ inicial de 0,070631 , formados diretamente a partir de rochas crustais (ou derivado de fonte mantélica, mas fortemente afetado por contaminação crustal) durante evento colisional continental. Santos \& Silva (1994, apud Souza, 2009), consideram tratar-se de uma suíte metaluminosa, cálcio-alcalina expandida (tipo-I cordilheirano), com evidências de acresção mantélica direta. Santos et al. (2000) relatam a dificuldade em distinguir esta suíte do 


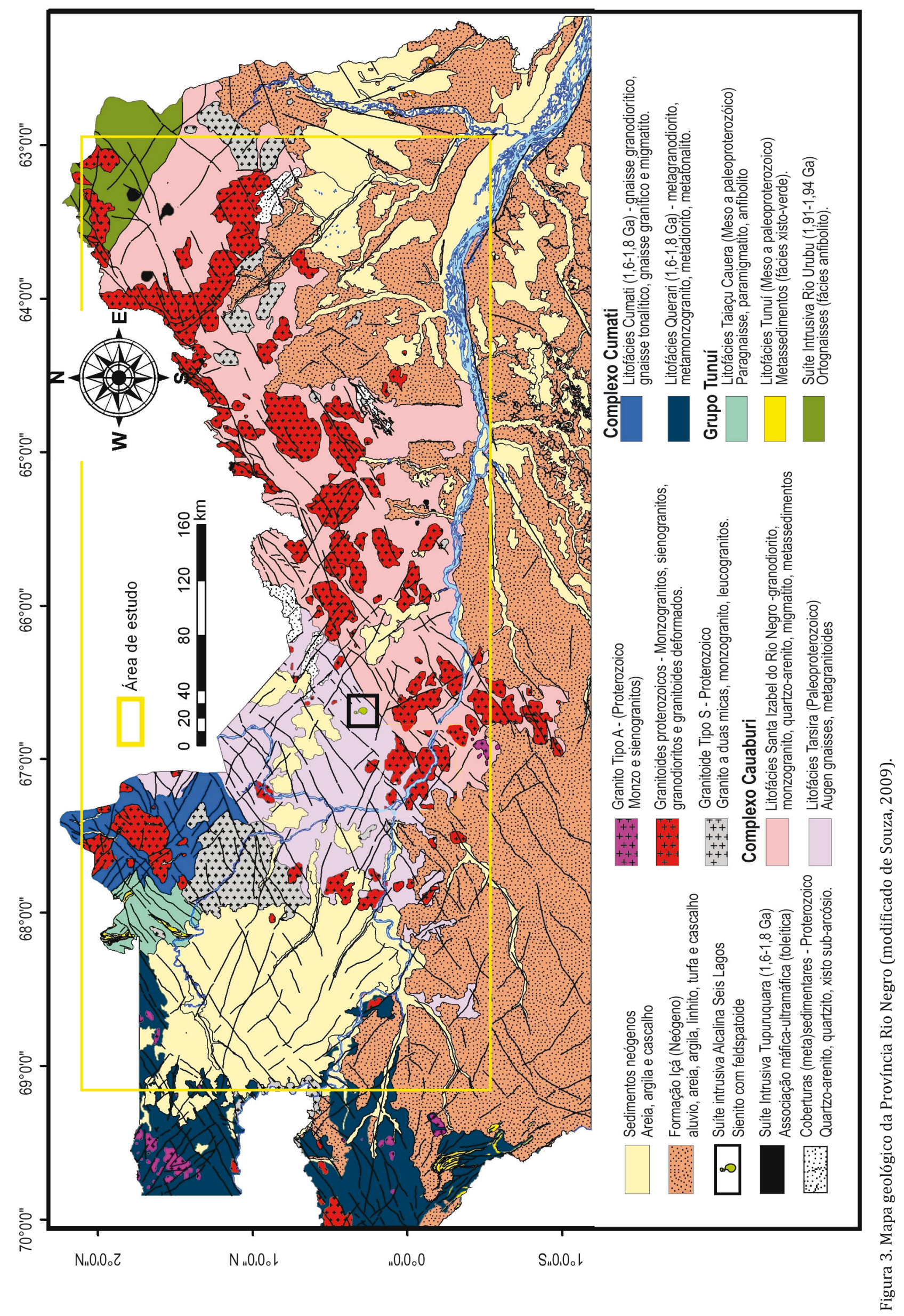


embasamento devido às similaridades químicas e mineralógicas e aos granitos serem sintectônicos e terem sido posteriormente cisalhados localmente pelo evento K'Mudku (1,2 Ga). Por outro lado, Souza (2009) caracterizou o Granito São Gabriel da Cachoeira, pertencente a esta suíte, como gerado por fusão parcial de uma fonte transamazônica dominantemente crustal, em ambiente de colisão em 1,5 Ga, e afetado por evento deformacional responsável pelas foliações $\left(\mathrm{S}_{0}\right.$ e $\left.\mathrm{S}_{1}\right)$ com direção NE e por cisalhamentos transcorrentes de mesma orientação, com idade próxima à idade de cristalização do granito, uma vez que se trata de um granito sintectônico à deformação regional. Quanto à atuação de eventos posteriores à colocação do granito, o referido autor admite que possam ter ocorrido, mas destaca a necessidade de mais estudos, inclusive no que tange ao evento K'Mudku, do qual pouco se conhece e não há consenso sobre sua idade, temperatura e estruturação.

\subsection{Complexo Carbonatítico Seis Lagos}

O complexo é composto por três estruturas aproximadamente circulares. A feição morfológica do MSL possui comprimento de $5 \mathrm{~km}$ (na direção N-S) e largura de 4,50 km (na direção E-W), enquanto que as estruturas menores apresentam diâmetros de 0,75 km e 0,50 km, respectivamente. No MSL, o relevo é pseudo-cárstico, com diversas depressões por colapso, algumas das quais originaram lagos.

Segundo Pinheiro et al. (1976), o posicionamento do complexo deve-se à reativação de antigas fraturas que obedecem a um controle estrutural dado pela interseção de dois lineamentos segundo as direções NW-SE e NE-SW, respectivamente. $\mathrm{O}$ depósito está associado a uma crosta laterítica formada pela alteração do carbonatito. Duas campanhas de sondagens foram realizadas (CPRM, 1976; CPRM, 1983), mas não se conhece a espessura total da crosta, já que os furos não a atravessaram totalmente; o mais profundo dos furos na crosta (SG-01-AM) foi interrompido na profundidade de $255 \mathrm{~m}$. 0 furo mais profundo no CCSL (SG-04-AM, com $492 \mathrm{~m}$ ) foi realizado numa bacia de origem cárstica, onde não ocorreu a formação de crosta laterítica.

Corrêa (1996) e Corrêa \& Costa (1997) efetuaram as primeiras investigações científicas no MSL, focando na mineralogia da crosta laterítica, na qual identificaram hematita e ghoetita, como os minerais mais abundantes, e hollandita, romanechita, pirolusita, lithioforita, florencita, cerianita, gibbsita, ilmeno-rutilo, brookita niobífera e rutilo niobífero, além de monazita, zircão e quartzo. A origem da crosta foi interpretada como produto de alteração de rocha carbonatítica, corroborando a proposta original da CPRM (1976). Giovannini (2013) subdivide a crosta em 6 tipos texturais/ composicionais, identificou como siderita carbonatito a rocha carbonática encontrada, que havia sido tentativamente classificada como beforsito (Pinheiro et al., 1976) e descreve, nesta rocha, os minerais siderita, barita, gorceixita, monazita e pirocloro. Não há dados de datação do carbonatito, de modo que a idade mesozoica proposta (Pinheiro et al., 1976; CPRM, 2006) baseia-se em correlações com diques de diabásio da região ou com corpos alcalinos situados mais a leste.

\subsection{Métodos}

0 estudo foi iniciado numa área de $650 \mathrm{~km}$ (E-W) por $300 \mathrm{~km}$ (N-S), indicada na figura 3. Subsequentemente, o estudo focou o CCSL e suas proximidades.

Para elaboração do modelo digital de elevação (MDE) foram utilizadas nove imagens do projeto Topodata, de $1^{\circ}$ de latitude por $1,5^{\circ}$ de longitude, cada, obtidas através do site do INPE (INPE, 2012). O Projeto Topodata oferece o Modelo Digital de Elevação (MDE) e suas derivações locais básicas em cobertura nacional, ora elaborados a partir dos dados SRTM (Shuttle Radar Topography Mission) disponibilizados pelo USGS na rede mundial de computadores (para mais detalhes ver Valeriano \& Rossetti, 2012). Através do software ENVI 4.5, foi gerado o mosaico das nove imagens que foram processadas com o software Global Mapper, utilizando a variável ZN, que corresponde aos valores de elevação do Topodata e sombreamento com aplicação de luz com azimute $45^{\circ}$ e inclinação de $45^{\circ}$, gerando um amplo mosaico, no qual, a cada intervalo altimétrico, foi atribuída uma cor, conforme a paleta de cores que acompanha as respectivas figuras do trabalho. 0 propósito deste MDE foi salientar as morfoestruturas da área de estudo, principalmente no embasamento cristalino, e realçar outros corpos passíveis de serem interpretados como análogos ao MSL. O mapa de morfoestruturas (lineamentos) foi gerado com base no mapa estrutural da CPRM e adensado em informações pela definição de lineamentos visualizados sobre o mosaico. Este processo foi realizado com auxilio do software ArcGis. Os mapas geológicos foram confeccionados a partir do mapa geológico da CPRM (2006), na escala 1:1.000.000 georreferenciado pelo datum WGS 84. Utilizando o software ArcGis, o mapa e o modelo digital de elevação 
foram sobrepostos e recortados de acordo com a área proposta para o trabalho, definida a partir do mosaico de imagens Topodata.

Os mapas geofísicos (aeromagnetométrico, aerogamaespectométrico e de anomalia Bouger) constam no mapa do Estado do Amazonas na escala 1:1.000.000 (CPRM, 2006). Eles foram sobrepostos, por transparência, aos mapas geológico, estrutural e ao mosaico gerado através dos arquivos Topodata. A região estudada se enquadra no domínio da Anomalia Magnética do Atlântico Sul, onde o campo magnético apresenta a menor intensidade de todo o globo e próxima do equador magnético, onde o campo magnético é aproximadamente horizontal.

Uma imagem de alta resolução do satélite SPOT 4, com pixel de $10 \mathrm{~m}$ foi utilizada para fins de detalhamento morfoestrutural da área do CCSL e análise de feições espectrais anômalas, cujo contraste permite a identificação de regiões de concentração de argilominerais, indicativos de possíveis zonas de alteração hidrotermal e também passíveis de concentrarem elementos terras raras. A área de estudo corresponde a um quarto da imagem original obtida pelo satélite, totalizando $225 \mathrm{~km}^{2}$, em composições coloridas falsa cor, cujas bandas espectrais correspondem aos comprimentos de onda do verde, vermelho, infravermelho próximo (IVP) e infravermelho de ondas curtas (IVOC). Os comprimentos de onda ( $\lambda$ ) são, respectivamente: 0,$540 ; 0,650 ; 0,835$; e $1,630 \mu \mathrm{m}$. 0 pré-processamento foi efetuado pelo método de ortorreferenciamento que gerou uma acuidade visual da ordem de $10 \mathrm{~m}$ em seu georreferenciamento e na projeção UTM, DATUM WGS84.

A sequência de processamentos foi efetuada pelo software ENVI 4.5, constando de: (a) recorte da imagem; (b) ajuste do "stretch" com redistribuição dos níveis de cinza da imagem nos 256 níveis possíveis, respeitando a proporcionalidade entre os níveis da imagem original (o stretch da imagem foi definido em 3\%); (c) tratamentos através de filtros diversos (passa alta, passa baixa, laplaciano, gausiano, mediano, Sobel e Roberts). 0 melhor resultado foi obtido com o filtro de convolução direcional utilizando máscaras $3 \times 3$ em intervalos de $15^{\circ}$, partindo de $0^{\circ}$ até $180^{\circ}$. Os diversos filtros foram empregados separadamente para cada banda da imagem e os melhores resultados foram alcançados nas bandas 3 (IVP) e 4 (IVOC); (d) combinações e análise de diferentes bandas espectrais gerando composições coloridas.

Entre as diversas combinações de bandas espectrais testadas, o melhor resultado foi alcançado através de combinação falsa cor, RGB, 234, na qual a banda 2 (banda do vermelho) é bastante destacada pela presença de ferro, a banda 3 (banda do infra vermelho próximo), bastante reflexiva pela vegetação, apresenta a cor verde, e a banda 4 (banda do infra vermelho de ondas curtas), na qual as argilas apresentam alta reflectância e aparecem na imagem em tons de azul. Tendo em vista a influência da posição do sol e a possibilidade da sobreposição de cores primárias gerando diferentes colorações no pixel, pode-se interpretar as cores da imagem colorida RGB como: verde representando a vegetação; vermelho, a crosta laterítica e áreas com concentração de ferro; e azul, as argilas.

\section{Resultados}

A maior parte da área de estudo é ocupada por uma planície de baixa altimetria, com pouca variação, não ultrapassando os $150 \mathrm{~m}$ em média (Fig. 4). Os terrenos de cota mais elevada (em vermelho) formam uma faixa fortemente orientada na direção NE-SW, sugerindo que esta pode tratar-se de um "bloco", limitado por estruturas com esta direção. Nesta faixa, ocorrem rochas do embasamento, granitos e metassedimentos (áreas mais altas, frequentemente acima de $2.000 \mathrm{~m}$ ), de modo que a sua estruturação é bem mais complexa. Como observado por CPRM (2006), a direção NW-SE é menos frequente, mas onde ocorre é muito marcante, como no alinhamento da Serra Curupira. A extremidade sudoeste da faixa de direção NE-SW parece ser delimitada por um lineamento de direção NW-SE e outro de direção E-W (Fig. 4). O CCSL situa-se no prolongamento da faixa para SW e no prolongamento, para oeste, do alinhamento E-W que marca o seu limite sul. Observa-se na figura 4 que o sistema de drenagem da área, tanto pelo rio Negro, como pelos rios de $2^{\underline{a}}$ e $3^{\underline{a}}$ ordens, é fortemente orientado, havendo grande predomínio da direção E-W. A borda da bacia sedimentar do rio Solimões também tem forte orientação segundo a direção E-W.

0 mapa gravimétrico (CPRM, 2006) não se mostrou eficiente para identificação de estruturas na área de estudo. Na área onde se situa o CCSL ocorre uma ausência de dados, claramente omitidos do mapa aerogamaespectométrico do Estado do Amazonas (CPRM, 2006). Não foi encontrada nas demais partes da área de estudo nenhuma anomalia positiva com a intensidade esperada (5.000 a 15.000 cps, conforme Pinheiro et al., 1976) para corpos semelhantes aos do CCSL.

O mapa aeromagnetométrico (relevo sombreado) (Fig. 5) mostrou-se altamente eficaz, com grande capacidade de separação de terrenos com 

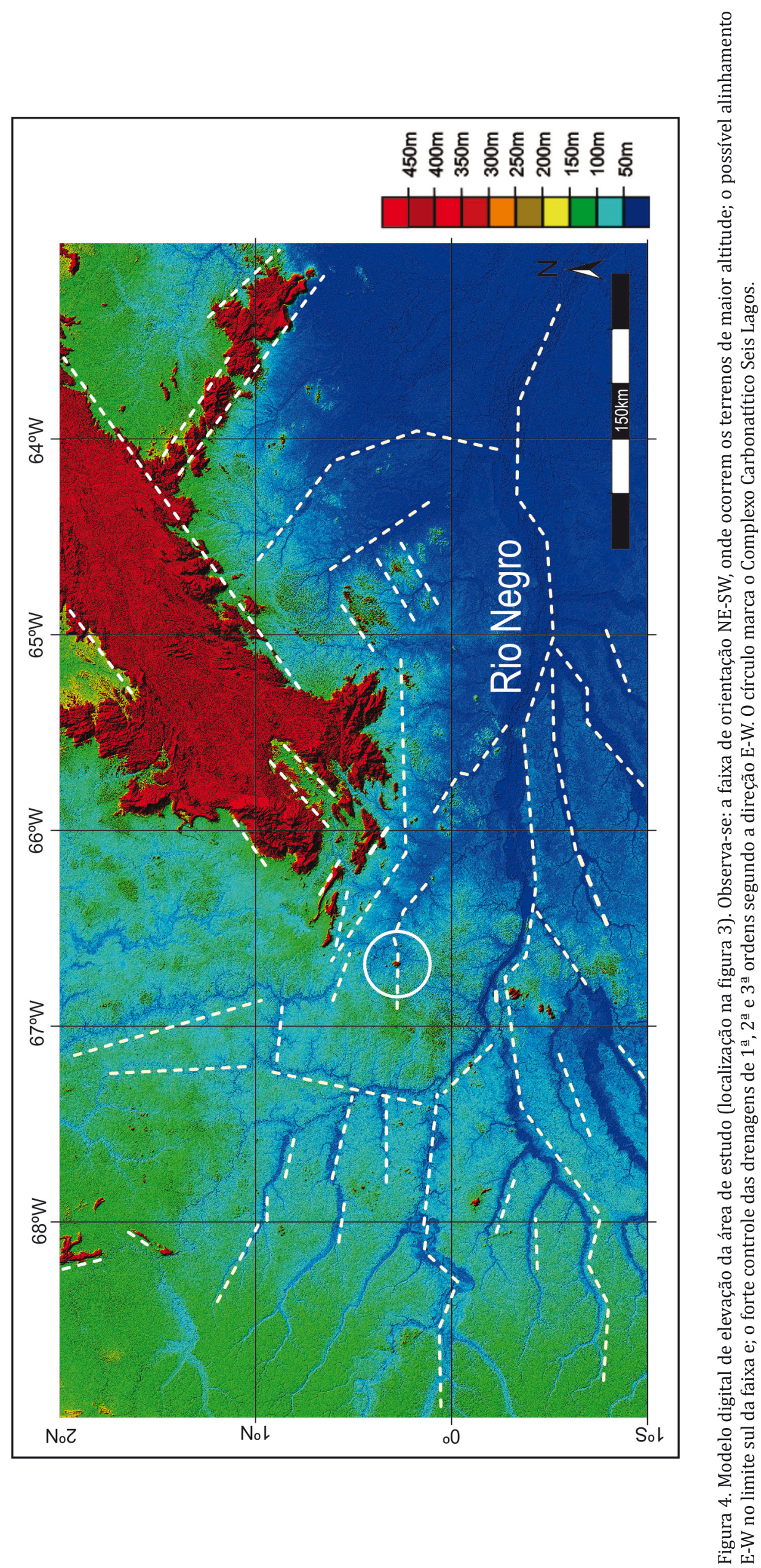
respostas distintas. O CCSL situa-se exatamente no limite entre um domínio de alta intensidade magnética, a norte, e um domínio de baixa intensidade, a sul. Este limite tem uma direção geral E-W e pode ser seguido continuamente por mais de 400 km (Fig. 5A). No trecho onde se situa o CCSL e mais a oeste deste (Fig. 5B), o contato entre os dois domínios é muito abrupto e faz inflexões alternadas para ENE-WSW e ESE-WNW, sugerindo um contato por falhamento. Na litofácies Santa Izabel do Rio Negro, o domínio de alta intensidade magnética poderia corresponder a uma série de corpos graníticos que em superfície (Fig. 3) ocorrem muito pró- ximos uns dos outros e, em subsuperfície, podem ter continuidade e fazer parte de um batólito alongado segundo a direção E-W. O domínio de baixa intensidade magnética corresponderia às rochas gnáissicas. Além disso, a posição da interface coincide com o alinhamento E-W que marca a extremidade sul da faixa de terrenos de maior altitude. É interessante notar que a faixa K'Mukdu faz uma inflexão para E-W na área próxima ao CCSL (Fig. 2). Não se observa nenhuma indicação no mapa geológico (Fig. 3) do que poderia corresponder a esta interface geofísica na litofácies Tarsira.

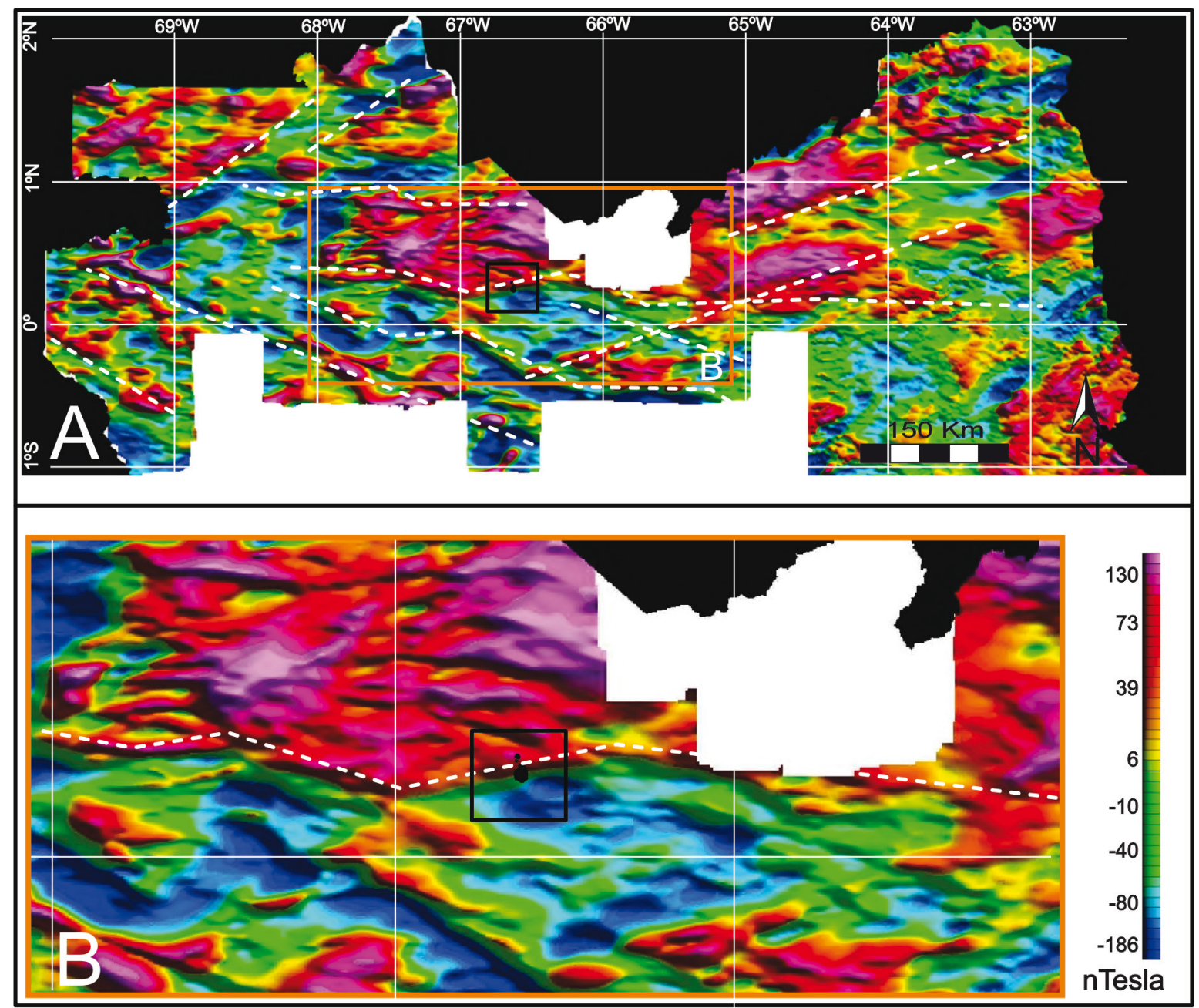

Figura 5. Mapa aeromagnetométrico (relevo sombreado), extraído de CPRM (2006). A) Área de estudo, observando-se a localização do CCSL (quadrado preto) sobre um lineamento de direção geral E-W que delimita dois domínios de intensidades magnéticas muito contrastantes; B) Área no entorno do complexo, observando-se as inflexões do lineamento alternadas para ENE-WSW e ESE-WNW, e o caráter muito abrupto da interface magnética.

As direções de morfoestruturas mais frequentes na área maior são NE-SW e NW-SE, e, subordinadamente, NNW-SSE e E-W (Fig. 6). Nesta figura, se observa duas faixas (destacadas pelo tracejado) nas quais as morfoestruturas de direções NW-SE e NE-SW ocorrem com maior densidade. A faixa de direção NE-SW coincide aproximadamente com o limite entre as litofácies do Complexo Cauaburi,
Santa Izabel do Rio Negro (a SE da faixa) e Tarsira (a NW da faixa), observado no mapa geológico (Fig. 3). Nota-se uma menor densidade de morfoestruturas na porção da área a SE desta faixa, em relação à região a NW da mesma. Não é possível atribuir com certeza esta distinção a diferenças estruturais, pois a porção da área onde a densidade de morfoestruturas é menor tem cotas mais baixas 
(Fig. 4), sendo, portanto, mais suscetível a inundações do rio Negro e seus afluentes, o que pode implicar o maior mascaramento dos lineamentos por sedimentos fluviais.

No entorno do CCSL (Fig. 7A), as morfoestruturas mais destacadas têm direção E-W; também ocorrem morfoestruturas NE-SW e WNW-ESE. Todas são marcadas principalmente pelos rios, cujos traçados altamente lineares indicam seus controles por falhas e fraturas. 0 corpo do morro dos Seis Lagos e um dos corpos menores situam-se, respectivamente, sobre os traços das duas principais estruturas da área, ambas de direção E-W (Fig. 7A). A estrutura mais ao sul controla um rio que, ao se aproximar do Morro dos Seis Lagos, circunda a parte sul do morro e, após contorná-lo, retoma a sua direção original, exatamente no prolongamento da mesma estrutura (Fig. 7). Na imagem de maior detalhe (Fig. 7B) observa-se que esta estrutura tem uma expressão muito clara dentro do corpo, controlando feições topográficas internas ao mesmo. Estas estruturas de direção E-W devem corresponder à expressão superficial do lineamento E-W identificado no mapa aeromagnetométrico (Fig. 5). As estruturas de direção NE-SW e NW-SE se enquadram nas duas faixas mostradas na figura 6 e devem ter exercido controle local no posicionamento dos corpos do complexo.

Na figura 7 observa-se que o formato circular/ovalado do MSL é conferido pelo contorno do seu sopé (verde brilhante no modelo digital de elevação). Em cotas mais elevadas (cores amarelo e vermelho), entretanto, o contorno é mais irregular e, no detalhe (Fig. 7B), observa-se uma forma mais semelhante a um polígono. 0 morro tem bordas abruptas e lineares em todos os lados do polígono, com exceção da borda NW, a qual também teve, presumivelmente, um caráter abrupto e linear na direção NE-SW, mas apresenta-se atualmente irregular, devido à existência de vales controlados por estruturas de direção NNW-SSE. A imagem SPOT (Fig. 8) confirma que o relevo no interior do morro é principalmente controlado por estruturas de direção NNW-SSE. Uma das raras exceções é dada pela estrutura de direção E-W que atravessa a parte sul do corpo. Na figura 8 - na qual a imagem SPOT foi tratada através de filtro linear, salientando estruturas de direção azimutal próximas a $150^{\circ}$ e utilizando a banda 3 (IVP) - observa-se a grande frequência de estruturas NNW-SSE sobre o morro e também nas suas cercanias.

A composição de bandas espectrais RGB 234 (Fig. 9) possibilitou definir com precisão os limites da crosta laterítica ferruginosa. 0 corpo principal de laterita ferruginosa cobre uma área de cerca de $8 \mathrm{~km}^{2}$. Alguns limites coincidem com aqueles inferidos a partir do modelo digital de elevação (Fig. 7B), como ocorre na borda SW, fortemente orientada na direção NW-SE, e na borda SE, orientada na direção NE-SW. Na borda E, ocorre um "corpo" alongado, aparentemente separado do corpo principal, que também é rico em Fe, mas com tom mais fraco do que o observado no-interior do corpo principal, podendo corresponder, portanto, a uma zona de laterita desenvolvida sobre a encaixante gnáissica. Configuração semelhante ocorre na borda norte, onde o "corpo" isolado tem uma orientação aproximadamente E-W. A reentrância

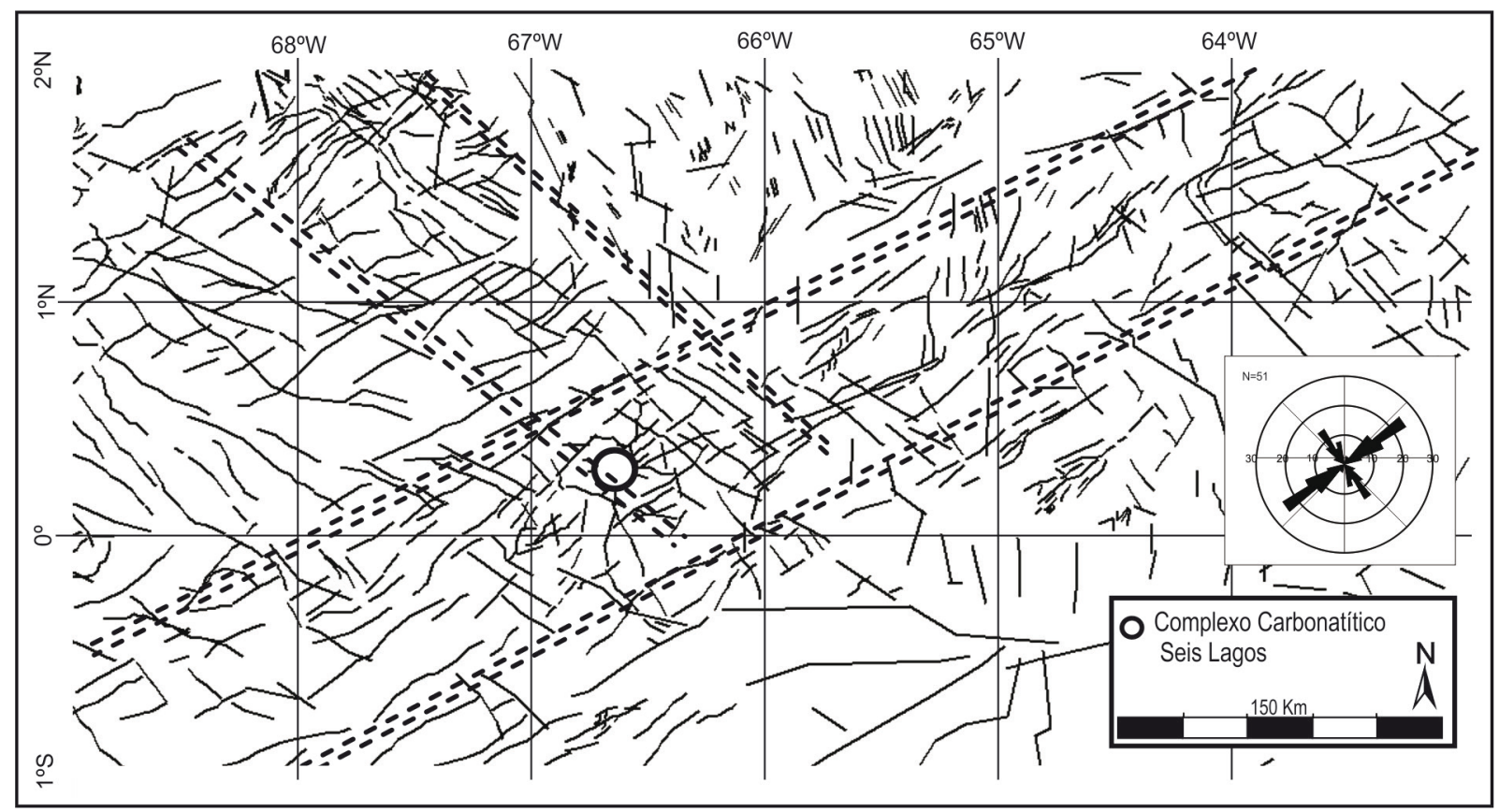

Figura 6. Principais morfoestruturas da área de estudo (retângulo amarelo da figura 3). 


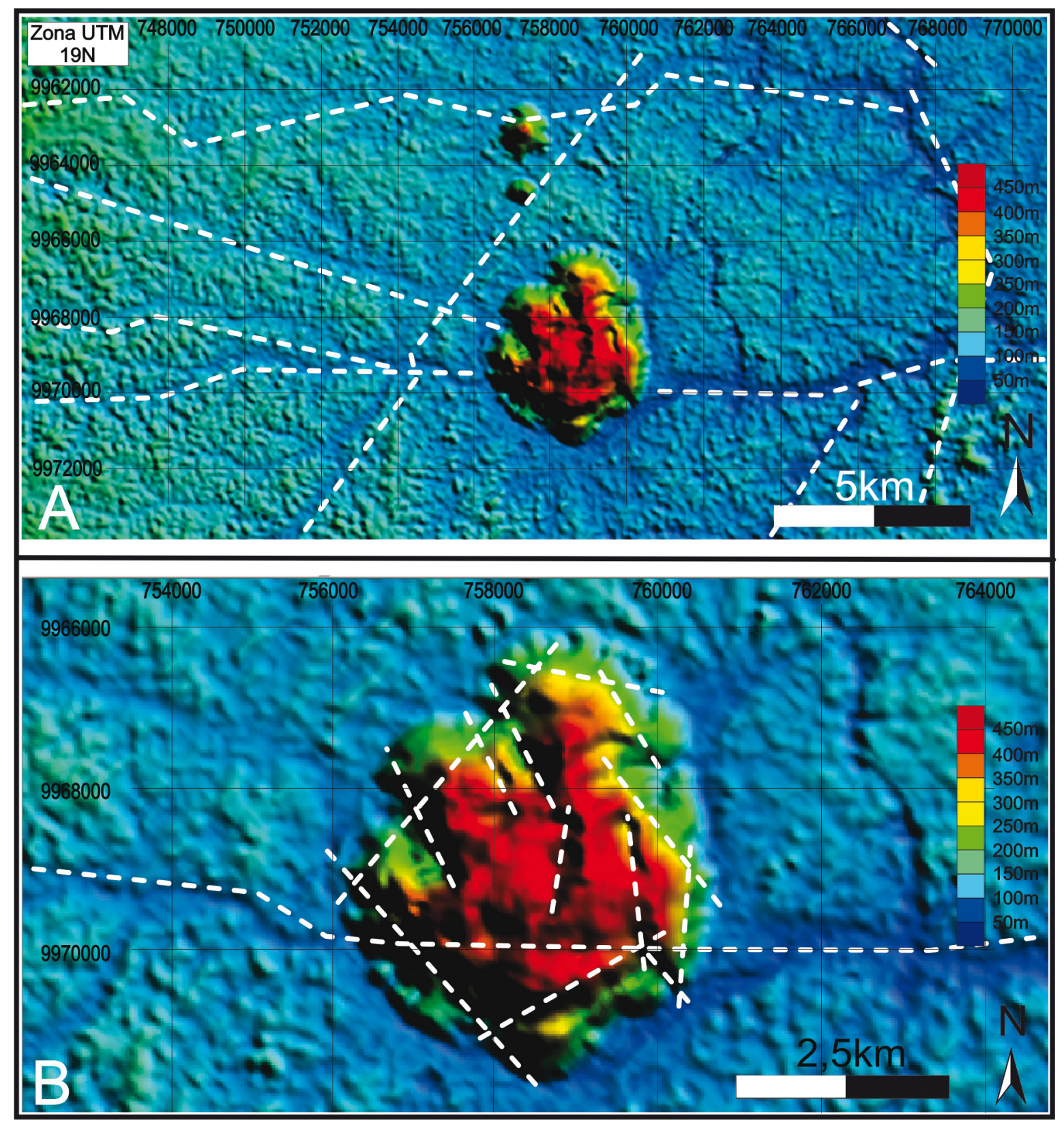

Figura 7. Principais morfoestruturas no entorno do Complexo Carbonatítico Seis Lagos (A) e no Morro dos Seis Lagos (B).

existente na borda NW está associada à erosão da laterita com a formação de um vale controlado por estrutura de direção NNE-SSW.

As áreas onde a resposta espectral é característica de argilas não ocorrem de forma destacada e apenas com uma análise cuidadosa é possível identificá-las (Fig. 9). Porém, a associação destas áreas com as estruturas é bem evidenciada pelas suas localizações e pelas suas formas alongadas (com exceção daquela marcada por um círculo) na mesma direção NNW-SSE ou N-S das estruturas (comparar com Fig. 7B). Adicionalmente, observa-se que pelo menos três dos lagos e algumas das depressões existentes sobre o morro parecem fazer parte destes alinhamentos, indicando que os processos cársticos, formadores dos lagos foram, pelo menos em parte, controlados pelas estruturas NNE-SSE a N-S. A figura 9 foi gerada através do tratamento da imagem do satélite SPOT, utilizando apenas a banda do IVOC. As elipses marcam as áreas cuja resposta espectral (áreas brancas, representando alta reflectância) indicam a presença de argilas. Quando comparada à figura 10 , observa-se que cinco das zonas com argilas se repetem, confirmando, assim, a eficácia das técnicas utilizadas. 


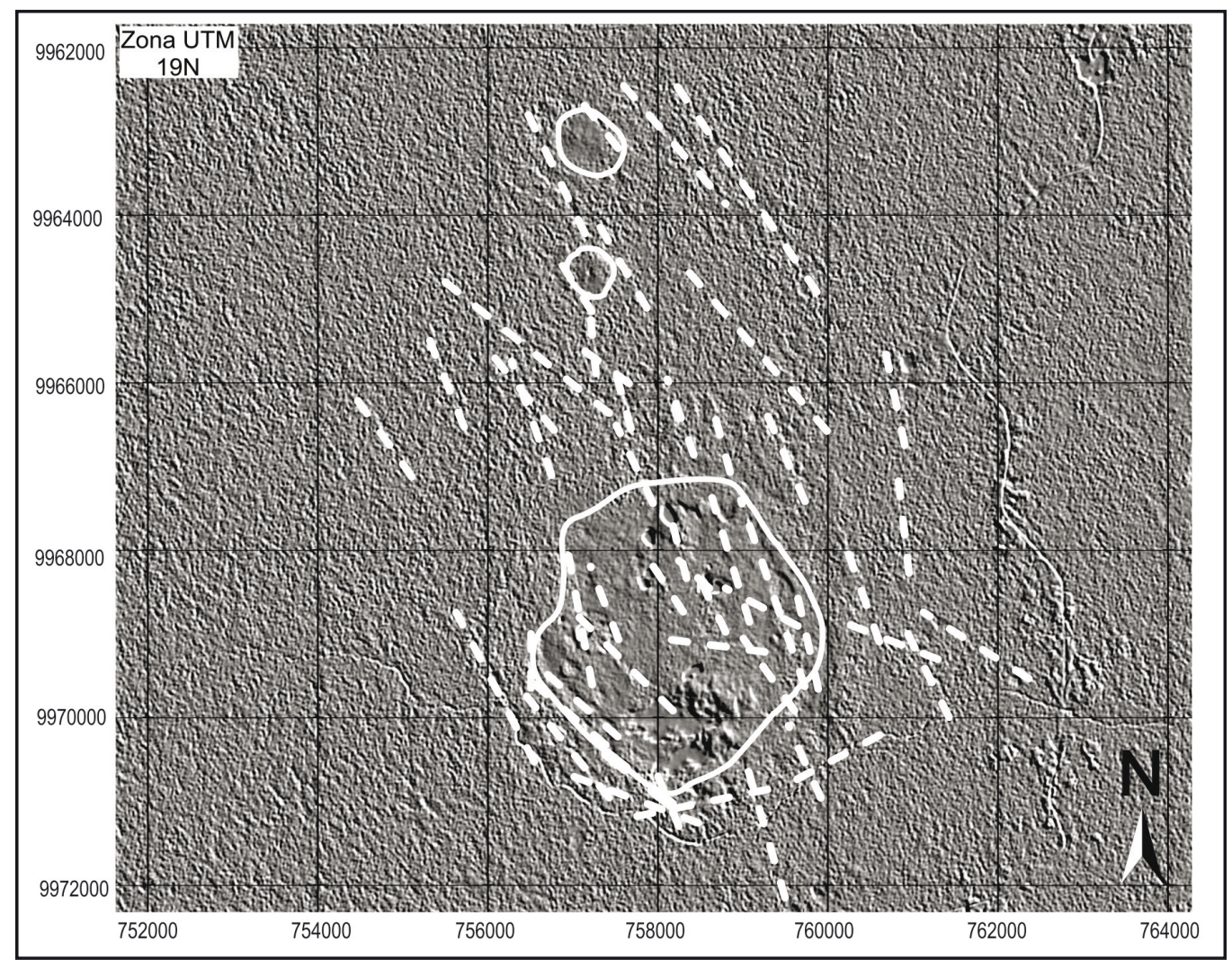

Figura 8. Imagem SPOT da área do Complexo Carbonatítico Seis Lagos tratada através de filtro linear, salientando estruturas de direção azimutal próximas a $150^{\circ}$ utilizando a banda 3 (IVP).

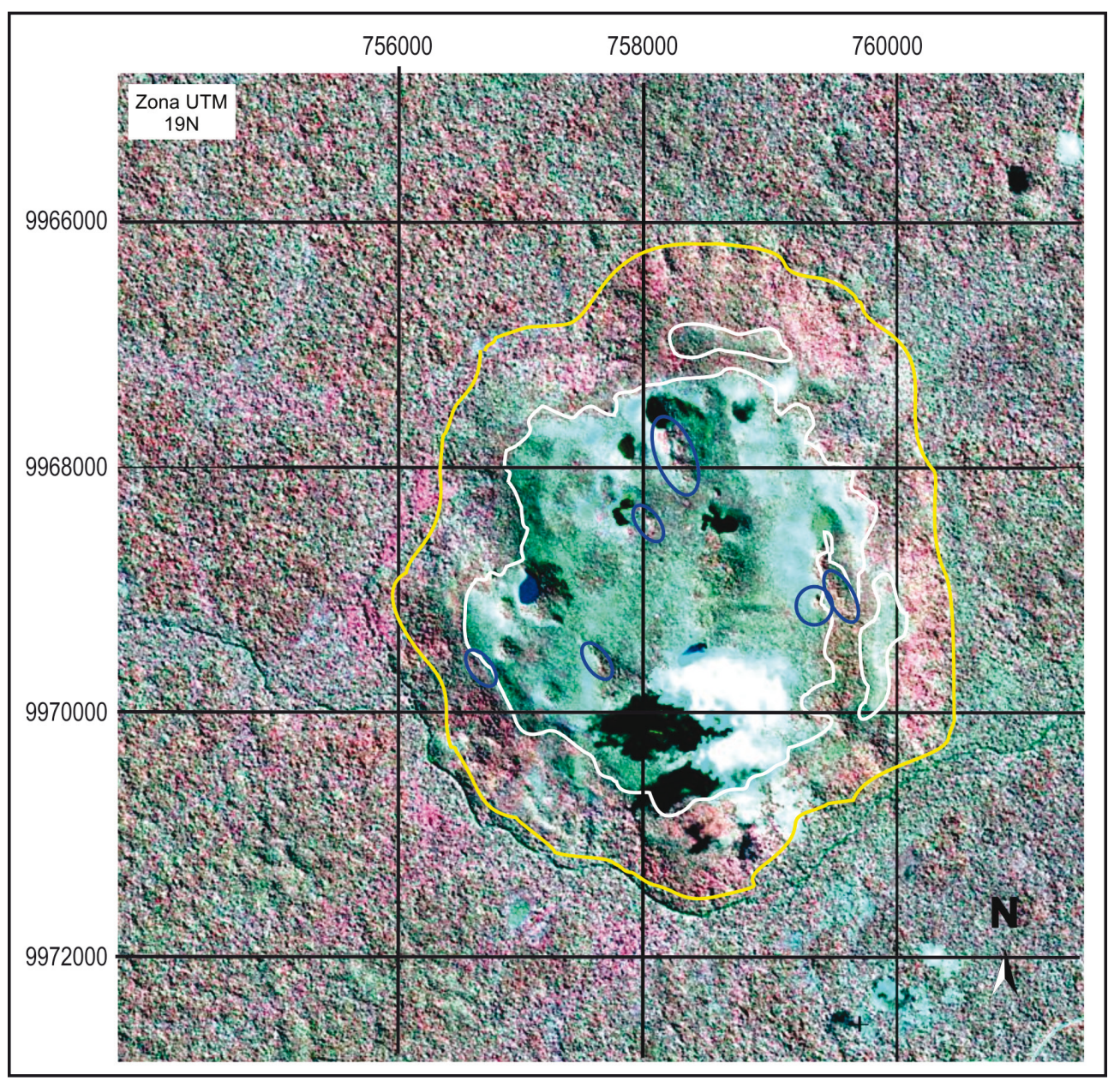

Figura 9. Morro dos Seis Lagos em composição colorida falsa cor sobre a imagem SPOT. A linha amarela delimita o sopé do morro; a linha branca delimita a crosta laterítica; as elipses azuis identificam zonas com resposta espectral característica de argila. 


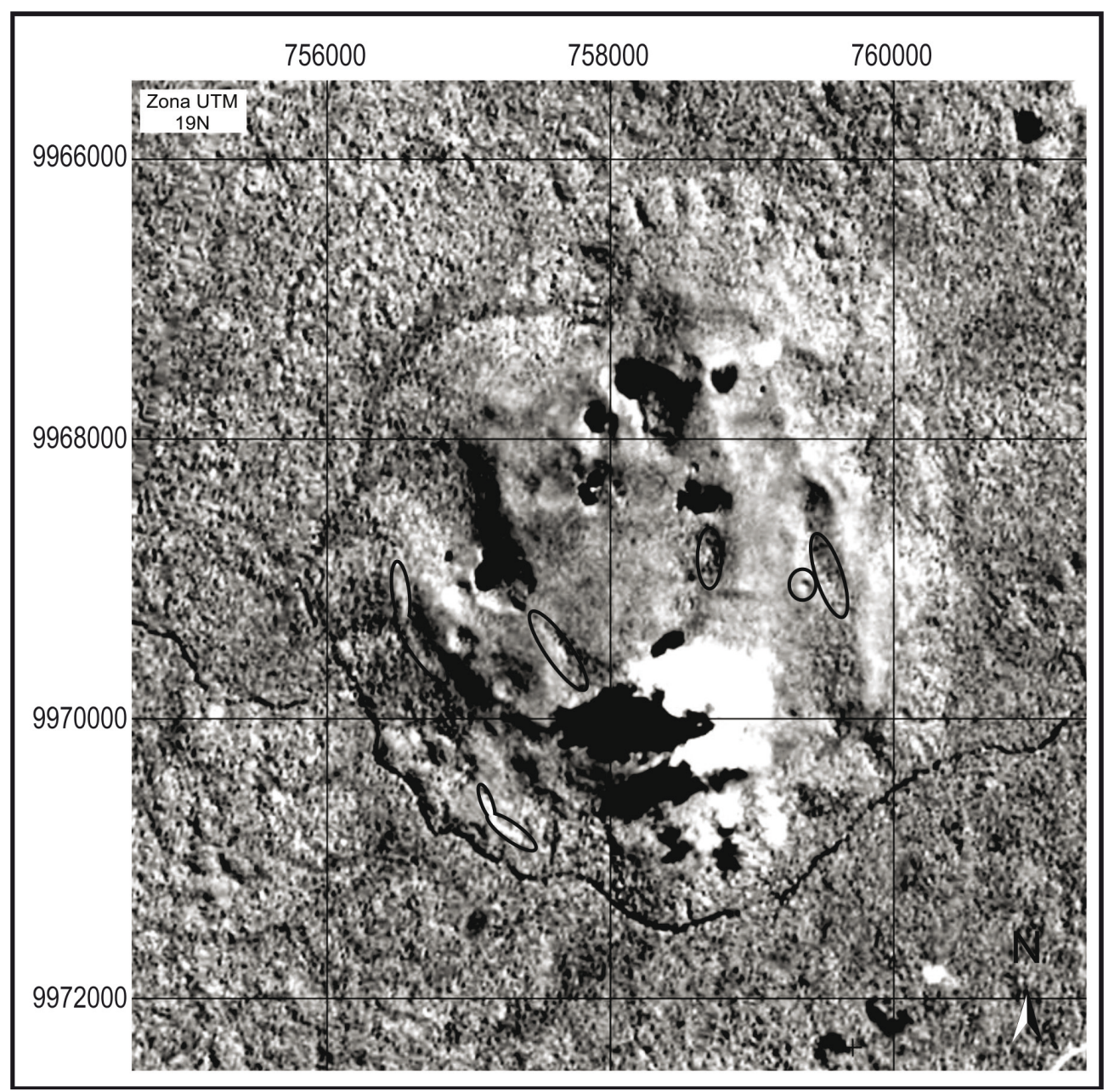

Figura 10. Resposta da imagem SPOT na área do Morro dos Seis Lagos utilizando apenas a banda do infravermelho de ondas curtas. As elipses pretas marcam áreas com resposta espectral indicativa da presença de argila.

\section{Discussão dos resultados}

\subsection{Controle do posicionamento do carbonatito}

Segundo os modelos petrogenéticos mais recentes, apoiados por grande número de dados isotópicos, os magmas parentais dos carbonatitos derivam de fontes mantélicas, sejam elas astenosféricas ou litosféricas. 0 controle principal sobre o posicionamento destes corpos é relacionado a megaestruturas que, muitas vezes, correspondem a descontinuidades crustais associadas a ambiente de rifte. Frequentemente, os corpos carbonatíticos distribuem-se ao longo de alinhamentos, como, por exemplo, aqueles encontrados no sudoeste da África e no oeste dos EUA e Canadá (Chakhmouradian \& Zaitsev, 2012). Neste sentido, é muito pertinente a proposta da CPRM (2006), que considera que o CCSL e diques de diabásio do Domínio Alto Rio Negro (correlacionados ao Diabásio Uaraná do Eojurássico ao Neotriássico) podem registrar correspondência com o evento magmático Taiano que antecedeu a instalação do Rifte Tacutu (Reis et al., 2006) no Domínio Guiana Central em Roraima, no prolongamento estrutural NE-SW do Domínio Imeri. Entretanto, não se conhece a idade do CCSL. Alternativamente, poder-se-ia aventar uma ligação do CCSL com os corpos carbonatíticos Maicuru e Mutum que estão aproximadamente alinhados na direção E-W com o CCSL, porém estes possuem idades muito distintas entre si, respectivamente: $586 \pm 18$ Ma (Lemos \& Gaspar, 1998) e 1.0 Ga (Gomes et al., 1990). Assim, enquanto a idade do CCSL não for conhecida, seu enquadramento em qualquer contexto geotectônico e/ou sua ligação com outro corpo carbonatítico são conjecturais.

Desde os trabalhos pioneiros do RADAM e CPRM, o controle do posicionamento do CCSL tem sido atribuído a estruturas de direção NE-SW e/ou NW-SE. De fato, o CCSL situa-se na intersecção de duas grandes estruturas com essas respectivas direções. Entretanto, a maior estrutura da região do CCSL é aquela de direção E-W e extensão de, pelo menos, $400 \mathrm{~km}$, interpretada a partir dos mapas aeromagnetométrico e cuja existência é sustentada pelas evidências aqui apresentadas. A forte orientação do sistema de drenagem segundo a di- 
reção E-W (tanto pelo rio Negro, como pelas drenagens de $2^{\underline{a}}$ e $3^{\underline{a}}$ ordens) e a orientação E-W da borda da bacia sedimentar do Solimões sugerem a existência na região de grandes estruturas com esta direção. Trata-se provavelmente de estruturas de idade proterozoica que podem ter sido diversas vezes reativadas (inclusive após o posicionamento do CCSL). É possível que esta estrutura seja relacionada ao evento K'Mudku, cuja faixa de ocorrência faz uma inflexão na direção E-W na região de estudo (Fig. 2). Sugere-se que o controle principal do posicionamento do CCSL foi exercido pela estrutura E-W e que, ao longo desta, a intrusão alojou-se onde ela é intersectada, no mesmo local, pelas faixas de estruturas de direção NE-SW e NW-SE.

0 processo de laterização implica a remoção de elementos e, consequentemente, uma importante redução de volume. Nos casos de Mount Weld (Lottermoser, 1990) e Mrima Hill (Coetzee \& Edwards, 1960) estimou-se que de cinco a dez volumes de carbonatito foram intemperizados para produzir um volume de laterita. No MSL, pode-se inferir uma redução da ordem de dez vezes, levando-se em conta os enriquecimentos médios de $\mathrm{Nb}$ e de Ti em relação ao carbonatito (Giovannini, 2013). Assim, a espessura mínima de $250 \mathrm{~m}$ para a crosta de Seis Lagos implica a lateritização de uma "coluna" de carbonatito da ordem de $2,5 \mathrm{~km}$ de altura.

\subsection{Forma e estrutura interna do carbonatito e im- plicações metalogenéticas}

Os limites da crosta laterítica delineados neste trabalho devem representar, de forma mais precisa, o formato original da intrusão, o qual contrasta com a forma circular do Morro dos Seis Lagos, cujo perímetro é hoje definido pelos depósitos de tálus. Os limites marcantemente retilíneos de boa parte da crosta sugerem que a forma do corpo carbonatítico seja controlada por estruturas rúpteis (falhas ou fraturas). Estas estruturas podem representar as paredes do conduto magmático, aberto, seguindo falhas e fraturas, ou podem ser falhas que afetaram o corpo após sua cristalização. Ao nível atual do conhecimento, não é possível discernir onde se aplica cada tipo.

A principal estrutura identificada no MSL situa-se na sua parte sul e coincide com o prolongamento, para dentro do corpo, da estrutura E-W que foi interpretada como a principal controladora da intrusão. A reativação desta estrutura formou internamente ao corpo uma crista acompanhada de um vale, ambos paralelos à direção E-W (Fig. 7B).
As demais estruturas identificadas têm direção NNW-SSE e, subordinadamente, $\mathrm{N}-\mathrm{S}$, e a elas estão associados vales e cristas com estas direções. Portanto, estas falhas controlaram processos erosivos que contribuíram para o modelamento do relevo. Entretanto, num carbonatito, outros fatores condicionam a evolução do relevo. Durante a lateritização, ocorre a remoção de elementos mais móveis e o consequente enriquecimento relativo em elementos menos móveis. 0 processo gera espaços vazios e o material pode perder a sustentação e colapsar. Além disto, em um carbonatito, pode ocorrer processos cársticos e consequente formação de relevo deste tipo. Os carsts aumentam muito a porosidade e a permeabilidade da rocha, fazendo com que a frente de lateritização atinja profundidades muito maiores do que em outras rochas. Assim, a formação dos carsts no carbonatito também pode ser guiada por falhas e fraturas. Consequentemente, a lateritização e o colapso também podem ser fortemente influenciados por estruturas. Isto significa que as estruturas que afetam o corpo de Seis Lagos possivelmente balizam zonas onde a laterita é mais espessa e/ou mais rica em Nb e ETR.

Outro interesse da identificação de estruturas relaciona-se com o hidrotermalismo, o qual pode ser muito acentuado em carbonatitos, originando o carbohidrotermalismo (Chakhmouradian \& Zaitsev, 2012), através do qual elementos e compostos químicos de interesse econômico podem formar acumulações anômalas. Em corpos carbonatíticos é relativamente comum a formação de fluorcarbonatos de ETR, como a synchysita e a parisita, em zonas mais fortemente hidrotermalizadas (Ruberti et al., 2008). Nestas zonas, os silicatos podem ter sido alterados para minerais de argila, razão pela qual foram utilizadas técnicas de sensoriamento remoto, capazes de separar os alvos terrestres através das diferentes respostas de absorção e reflectância das ondas detectadas pelos satélites e radares orbitais, identificando assim as regiões com concentrações de argilominerais. Neste trabalho foram identificadas oito zonas com reflectâncias típicas de argilas. A associação destas zonas com estruturas é muito evidente: as quatro zonas de argilas situadas internamente ao corpo estão associadas a quatro estruturas NNW-SSE, cada uma destas, por sua vez, perfeitamente alinhada com um lago ou depressão; duas zonas localizam-se na borda SW, justamente a borda mais retilínea e supostamente controlada por falha. Estas quatro estruturas representam, portanto, locais a serem investigados detalhadamente em futuros trabalhos no MSL. 


\section{Conclusões}

O posicionamento dos corpos do CCSL teve como controle principal uma estrutura de direção geral E-W, com uma extensão de cerca de $400 \mathrm{~km}$, ao longo do Domínio Imeri. Na litofácies Tarsira, a estrutura se expressa em superfície na forma de falhas de direção E-W, com traços bem definidos, sobre os quais se localizam os dois maiores corpos do complexo. Ao longo desta estrutura E-W, o posicionamento dos corpos ocorreu onde ela é intersectada, no mesmo local, por duas faixas de estruturas de direção NE-SW e NW-SE.

Os limites da crosta laterítica aqui definidos devem representar o formato original do corpo no nível estrutural atualmente exposto, o qual corresponde a uma profundidade mínima de 2,5 km. Estes limites são em grande parte retilíneos, sugerindo estruturas rúpteis, sejam estas as paredes do conduto magmático, aberto seguindo falhas e fraturas, ou falhas que afetaram o corpo após sua cristalização. A principal estrutura interna ao corpo relaciona-se diretamente à própria falha E-W que controlou seu posicionamento, a qual foi reativada e formou uma crista acompanhada de um vale, ambos paralelos à direção E-W. O corpo foi também afetado por diversas falhas de orientação NNW-SSE, que também controlaram a formação de vales e cristas paralelos às mesmas, assim como os processos cársticos que formaram alguns dos lagos. Consequentemente, essas estruturas exerceram um papel relevante durante o processo de lateritização que formou o depósito de $\mathrm{Nb}$ a partir do carbonatito. Portanto, estas estruturas representam zonas onde pode ter ocorrido a formação de laterita mais espessa e mais enriquecida em $\mathrm{Nb}$ (e ETR). Em quatro destas estruturas foram identificadas zonas ricas em argilas, cuja formação pode ter sido relacionada a processos hidrotermais os quais, por sua vez, também podem contribuir para um enriquecimento do minério ao longo das estruturas NNE-SSW. Estas representam, portanto, zonas que devem ser investigadas mais detalhadamente em trabalhos futuros no MSL.

Agradecimentos- Os autores agradecem ao CNPq (proc. 483191/2010-8 e proc. 485415/2012-7) pelo apoio ao projeto, ao geólogo Antonio Gilmar de Souza (CPRM) pela colaboração e aos revisores pelas valiosas contribuições. Este trabalho é dedicado ao geólogo da CPRM Mateus Marcili dos Santos Silva (in memoriam).

\section{Referências}

Almeida, M.E., Macambira, M.J.B., Reis, N.J., Luzardo, R. \& Pinheiro, S.S. 2007. Geologia, geoquímica multielementar e isotópica ( $\mathrm{Sm}-\mathrm{Nd}$ ) das rochas do embasamento do extremo oeste da Província Rio Negro, NW do Amazonas, Brasil. In: SIMPÓSIO DE GEOLOGIA DA AMAZÔNIA, 10., 2007, Porto Velho. Anais... Porto Velho, SBG, v. 1, p. 26-29.

Bonow, W.C. \& Issler, R.S. 1980. Reavaliação e aspectos econômicos do jazimento de terras raras e ferro-ligas do lago esperança, Complexo Carbonatítico dos Seis Lagos - Amazonas, Brasil. In: CONGRESSO BRASILEIRO DE GEOLOGIA, 31., 1980, Balneário Camboriú. Anais... Balneário Camboriú, SBG, v. 3, p. 1431-1443.

Chakhmouradian, A.R. \& Zaitsev, A.N. 2012. Rare Earth Mineralization in Igneous Rocks: Sources and Processes. Elements, 8: 347-353.

Coetzee, G.L. \& Edwards, C.B. 1960. The Mrima Hill carbonatite, Cost Province, Kenya. Transactions of the Geological Society of South Africa, 62: 373-397.

CPRM. Serviço Geológico Brasileiro. 1976. Projeto Seis Lagos, v. 1. Manaus, CPRM, 136p. Relatório Final

CPRM. Serviço Geológico Brasileiro. 1983. Projeto Uaupés. Manaus, CPRM, 214p. Relatório Final.

CPRM. Serviço Geológico Brasileiro. 2002. Reconhecimento geológico ao longo dos rios Negro, Xié e Içana (Missão Tunuí), Noroeste do Estado do Amazonas. Superintendência Regional de Manaus, CPRM, 16 p. (Relatório interno).

CPRM. Serviço Geológico Brasileiro. 2006. Geologia e Recursos Minerais do Estado do Amazonas. Manaus. CPRM, 144p.

Cordani, U.G. \& Brito Neves, B.B. 1982. The Geologic Evolution of South America during the Archean and Early Proterozoic. Revista Brasileira de Geociências, 12(1-3): 78-88

Corrêa, A.S. 1996. Evolução geoquímica da crosta laterítica e dos sedimentos sobrepostos na estrutura de Seis Lagos (Amazonas). Manaus, 212p. Tese de doutorado, Programa de Pós Graduação em Geociências, Instituto de Geociências, Universidade Federal do Pará.

Corrêa, A.S. \& Costa, M.L. 1997. Mineralogia das crostas laterítica ferruginosas de Seis Lagos (Amazonas). Revista Brasileira de Geociências, 16: 141-156.

Dall' Agnol, R. \& Macambira, M.J.B. 1992. Titanita-biotita granitos do baixo rio Uaupés, Província Rio Negro, Amazonas. Parte I: geologia, petrografia e geocronologia. Revista Brasileira de Geociências, 22(1): 3-14.

Giovannini, A.L. 2013. Contribuição à geologia e geoquímica do carbonatito e da jazida (Nb, ETR) de Seis Lagos (Amazonas). Porto Alegre, 128p. Dissertação de Mestrado, Programa de Pós-graduação em Geociências, Instituto de Geociências, Universidade Federal do Rio Grande do Sul.

Gomes C.B., Ruberti, E. \& Morbidelli, L. 1990. Carbonatite complexes from Brazil: a review. Journal of South America Earth Science (3/1): 51-63.

INPE. Instituto Nacional de Pesquisas Espaciais. 2012. 
Disponível em: <http://www.dsr.inpe.br/topodata>. Acesso em: 05 jun. 2012

Issler, S.R. 1980a. The Seis Lagos Carbonatite Complex. In: CONGRESSO BRASILEIRO DE GEOLOGIA, 31, Balneário Camboriú. Anais... Balneário Camburiú, SBG, v. 3, p. 1564-1573.

Issler, S.R. 1980b. Rare Earth Elements in the Seis Lagos Carbonatite Complex. Mineração e Metalurgia, 417: 20-30.

Justo, L.J.C.L. \& Souza, M.M. 1984. Jazida de Nióbio do Morro dos Seis Lagos. In: SIMPÓSIO DE GEOLOGIA DA AMAZÔNIA, 2, 1984, Manaus, Anais... Manaus, SBG, p. 467-672.

Justo, L.J.E.C. \& Souza, M.M. 1986. Jazida de Nióbio do Morro dos Seis Lagos, Amazonas. In: Schobbenhaus, C., Coelho, C.E.S. (coords.). Principais Depósitos Minerais do Brasil. Departamento Nacional de Produção Mineral - Companhia Vale do Rio Doce, Brasília, II: p. 463-468.

Lemos, R.L. \& Gaspar, J.C. 1998. Geologia do Complexo Ultramáfico-alcalino-carbonatítico de Maicuru, noroeste do estado do Pará. In: CONGRESSO BRASILEIRO DE GEOLOGIA, 40, 1998, Belo Horizonte. Anais... Belo Horizonte, SBG, v.1, p. 466-529

Lottermoser, B. G. 1990. Rare-earth element mineralization within the Mt. Weld carbonatite laterite, Western Australia -Lithos, 24(2): 151-167.

Pinheiro, S.S., Fernandes, P.E.C.A., Pereira, E.R., Vasconcelos, E.E., Pinto, A.C., Montalvão, R.M.G., Issler, R.S., Dall'Agnol, R., Teixera, W. \& Fernandes, C.A.C. 1976. Geologia. In: RADAM BRASIL - LEVANTAMENTO DE RECURSOS NATURAIS. V. 11. Folha NA-19 Pico da Neblina. 369p.

Reis N.J., Szatmari P. \& Wanderlei Filho J.R. 2006. Dois eventos de magmatismo máfico mesozóico na fronteira Brasil - Guiana, Escudo das Guianas: enfoque à região do rifte Tacutu - North Savannas. In: CONGRESSO BRASILEIRO DE GEOLOGIA, 43, 2006, Aracaju. Anais... Aracaju, SBG, v. 1, p. 459-464.

Ruberti, E., Enrich, G.E.R. \& Gomes, C.B. 2008. Hidrotermal REE fluorcarbonate mineralization at Barra do Itapirapuã, a multiplistockworkcarbonatite, southern Brazil. The Canadian Mineralogist, 46: 901-914.

Santos, J.O.S., Hartmann, L. A., Gaudette, H. E., Groves, D.I., Mcnaugthon, N.J. \& Fletcher, L.R.A.2000. New understanting of the Provinces of Amazon Craton based on Integration of Field Mapping and $\mathrm{U}-\mathrm{Pb}$ and Sm-Nd geochronology. Gondwana Research, 3(4): 453-488.

Santos, J.O.S. 2003. Geotectônica dos Escudos das Guia- nas e Brasil Central. In: Bizzi, L.A., Schobbenhaus, C., Vidotti, R.M. \& Gonçalves, J.H. (Eds.). Geologia tectônica e recursos minerais do Brasil: texto, mapas e SIG. Brasília, CPRM - Serviço Geológico do Brasil, p. 168-226.

Santos J.O.S., Van Breemen O.B., Groves D.I., Hartmann L. A., Almeida M.E., McNaughton N.J. \& Fletcher, I.R. 2004. Timing and evolution of multiple Paleoproterozoic magmatic arcs in the Tapajós Domain, Amazon Craton: constraints from SHRIMP and TIMS zircon, baddeleyite and titanite U-Pb geochronology. Precambrian Research, 131(10): 73-109.

Santos, J.O.S., Hartmann, L.A., Faria, M.S., Riker, S.R., Souza, M.M., Almeida, M.E. \& McNaughton, N.J. 2006. A compartimentação do cráton amazônico em províncias: avanços ocorridos no período de 2000-2006. In: SIMPÓSIO DE GEOLOGIA DA AMAZÔNIA, 9., 2006, Seção Temática 3, Belém, Pará. CD-ROOM.

Service, R.F. 2010. Nations move to head off shortages of rare earths. Science 26(327): 1596-1597.

Souza, A.G.H. 2009. Petrologia e geoquímica do batólito granítico São Gabriel da Cachoeira, Província Rio Negro, AM. Manaus, 89p. Dissertação de Mestrado, Programa de Pós-Graduação em Geociências, Instituto de Ciências Exatas, Universidade Federal do Amazonas.

Souza A.G.H., Nascimento R.S.C., Navarro, T.A., Almeida, M.E. \& Souza, V.S. 2009. Geoquímica do granito São Gabriel da Cachoeira (AM), Suíte Intrusiva Rio Uaupés. In: SIMPÓSIO DE GEOLOGIA DA AMAZÔNIA, 11, 2009, Manaus, Anais..., Manaus. p. 80-85

Stone, R. 2009. As China's rare earth R\&D becomes ever more rarefied, others tremble. Science, 325: 13361337.

Tassinari, C.C.G. 1981, Evolução tectônica da Província Rio Negro-Juruena na Região Amazônica. São Paulo, 99p. Dissertação de Mestrado, Instituto de Geociências, Universidade de São Paulo.

Tassinari, C.C.G. \& Macambira, M.J.B. 1999. Geochronological Provinces of the Amazonian Cráton. Episodes, 22(3): 174-182.

Tassinari, C. C. G. \& Macambira M. J. B. 2004. A Evolução Tectônica do Cráton Amazônico. In: Manteso-Neto, V., Bartoreli, A., Carneiro, C.D.R. \& Brito Neves, B.B. (Eds.). Geologia do Continente Sul Americano: Evolução da Obra de Fernando Flávio Marques de Almeida. São Paulo. Ed. Beca, p. 471-486.

Valeriano, M.M. \& Rossetti, D.F. 2012. Topodata: Brazilian full coverage refinement of SRTM data. Applied Geography, 32: 300-309.

Man. 555.

Editores: Tatiana Silva da Silva \& Maria do Carmo Lima e Cunha. 
